\title{
Von Abtrittanbietern und Silhouettenschneidern
}

\section{Erhard Taverna}

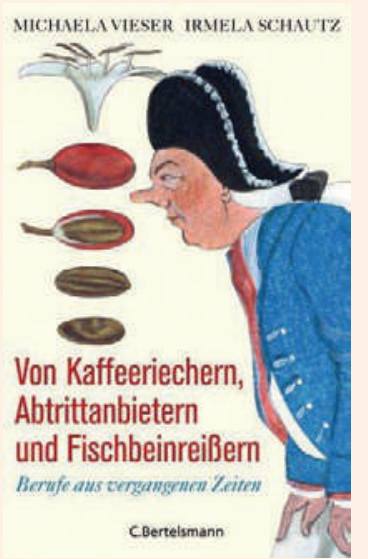

Michaela Vieser, Irmela Schautz Von Kaffeeriechern, Abtrittanbietern und Fischbeinreißern

Berufe aus vergangenen Zeiten München: Pantheon; 2012. 239 Seiten. $21.90 \mathrm{CHF}$ ISBN 978-3-5705-5195-0
Ältere Semester erinnern sich noch an Hufschmiede, Milchmänner, Scherenschleifer, Telefonistinnen und Kino-Platzanweiser. Sie sind verschwunden, wie die Schriftsetzer, Nachtwächter, Seifensieder und Gaslaternenanzünder. Mit der sich rasant ändernden Arbeitswelt sterben alte Berufe aus und neue entstehen. Absehbar museal werden Buchhändler, Allgemeinpraktiker und Hausabwarte. Einige Tätigkeiten bekommen neue Namen, bevorzugt in englischer Sprache, ohne konkreten Hinweis auf ein Handwerk, andere sind zeitgemäss etikettiert, zum Beispiel Mechatroniker, Raumkosmetikerinnen oder Gesundheitsfachfrauen. Jemand wird immer Brot backen oder Menschen behandeln, deswegen müssen sie nicht Bäcker oder Ärzte heissen. Berufsprofile verändern sich, neue Techniken erfordern veränderte Ausbildungen, der gesellschaftliche Wandel bestimmt die Funktion.

Über die Kulturgeschichte verlorener Berufe ist schon viel geschrieben worden. Wer eine vergnügliche Zeitreise unternehmen will, findet eine knappe und dennoch informative Lektüre in einem kürzlich verlegten, hervorragend bebilderten Taschenbuch «Von Kaffeeriechern, Abtrittsanbietern und Fischbeinreissern». Eine Zivilisationsgeschichte von Anbietern und Bedürfnissen als heilsame Relativierung vermeintlicher Unentbehrlichkeit. Dass Scharfrichter über lange Zeit den akademisch geschulten Ärzten den Rang abliefen, ist bekannt. Die europäischen Medici sezierten Schweine und lernten klug reden, die Praxis überliessen sie den Quacksalbern und Chirurgen. Wer köpfte und räderte, besass anatomische Kenntnisse, vertrieb begehrte Heilmittel wie zerlassenes Menschenfett oder Zaubermittel wie Diebesdaumen und Schamhaare. Da er auch Tierkadaver beseitigte, wilde Hunde tötete und Pferde und Rinder kastrierte, war er ein nützlicheres Mitglied der Gesellschaft als die meist eingebildeten Lateiner. Wie grundlegend sich unser Hygieneverständnis verändert hat, zeigt die über 100-jährige Profession der Abtrittanbieter, Kennzeichen: «langer Mantel, zwei Eimer, starker Geruch». Er oder sie waren eine unentbehrliche Institution, denn es gab weder öffentliche noch private Toiletten. 1694 schrieb die Herzogin Liselotte von der Pfalz: «Sie sind in der glücklichen Lage, scheissen gehen zu können, wann sie wollen (...) hier bin ich verpflichtet, meinen Kackhaufen bis zum Abend aufzuheben (...) das ärgert mich, weil ich bequem scheissen möchte, und ich scheisse nicht bequem, wenn sich mein Arsch nicht hinsetzen kann.» Noch Schiller und Goethe, auch sie in der Wortwahl nicht zimperlich, sollen die offene Sprache der Autorin bewundert haben. Männer und Frauen sorgten auf Märkten und Messen für den mobilen Toilettendienst. Wer sich erleichtern wollte, wurde mit einem langen Ledermantel umwickelt, aus dem nur der Kopf schaute. Bis Mitte des 19. Jahrhunderts waren die Anbieter im Geschäft, ganz nach dem alten römischen Motto: «Bene caca et irruma medicos - kacke gut und scheiss auf die Ärzte.»

Anspruchsvoller, wenn auch kurzlebiger, war der Scherenschnitt oder die Porträtsilhouette, die Adel und Gebildete und bald auch das gemeine Volk beschäftigte, Kennzeichen: «Schere in der Hand, durchdringender Blick». «Man lässt jetzt seinen Schatten besehen, wie ehemals sein Wasser», lästerte Lichtenberg über die modische Raserei mit der Schere. Zuerst ging es um mehr als nur eine Vorläufertechnik der Fotografie, denn mit Caspar Lavaters Physiognomie geriet das Schattenprofil zur Charakterstudie. Ab 1780 tauchten die ersten Berufssilhouetteure auf, deren Kunst im Biedermeier die populärste Zeit erlebte. Noch bis zur Erfindung des Polaroids lebten Künstler von diesen Schnipseln, die ihren Namen einem Finanzkontrolleur verdanken. Denn wieder einmal erforderte eine marode Finanzlage innovative Ideen. $\mathrm{Zu}$ den Sparmassnahmen des Barons de Silhouette gehörte der geniale Vorschlag, die gemalten Porträts teurer Ahnengalerien durch die weit billigeren Papierschnitte zu ergänzen. England lieferte dazu die Erfindung der Silhouettiermaschine. Dazu genügten eine Lampe, eine Glasscheibe und ein Storchenschnabel zur Übertragung und Verkleinerung.

Die Japanologin und Journalistin Michaela Vieser, u. a. für Geo, NZZ und taz tätig, hat 24 Berufe vergangener Zeiten gründlich recherchiert und zu eindrücklichen und humorvollen Vignetten verarbeitet. Die Grafikerin und wissenschaftliche Zeichnerin Irmela Schautz hat sie illustriert. Ameisler treten auf, Urinwäscher, Kaffeeriecher, Rosstäuscher, Märbelpicker und Sandmänner. Am längsten überlebte die Rohrpostbeamtin mit der Einführung der Rohrpost 1863 in England bis zum letzten Versand in Paris 1984. Für das meist weibliche Hantieren mit Druckluft war eine Berufskleidung vorgeschrieben und natürlich das Bestehen einer praktischen und theoretischen Prüfung. Das Leitungsnetz muss riesig gewesen sein, man fragt sich, was aus diesen Röhren geworden ist. 